\title{
Trends in Incidence of Skin Neoplasms other than Melanoma Malignum (C44 ICD-10) in Lower Silesia Region of Poland in Years 2006-2012
}

\author{
Jaroslaw Drobnik ${ }^{1}$, Magdalena Michalska ${ }^{2}$, Robert Suslo ${ }^{1}$ * \\ ${ }^{I}$ Gerontology Unit, Public Health Department, Wroclaw Medical University, Wroclaw, Poland \\ ${ }^{2}$ Non-Public Medical Care Facility - Strzelin Medical Center, Strzelin, Poland
}

\begin{abstract}
:
Skin neoplasms pose serious and increasing health threat in Poland that depends on UV exposure intensity linked to geographic location. Data on registered medical interventions because of skin neoplasms other than melanoma malignum (C44-C44.9 according to ICD-10) in years 2006-2012, made available due to courtesy of public healthcare insurance provider Narodowy Fundusz Zdrowia in Lower Silesia region of Poland (NFZ), were analysed in order to estimate yearly incidence and current relevant trends in Lower Silesia's population. The study revealed dynamic rising trend in non-melanoma skin neoplasms yearly incidence, their most common location was face, less often: trunk, scalp and neck.
\end{abstract}

Keywords: Skin Cancer; Dermatology; Oncology; Health Statistics; Public Health

\section{INTRODUCTION}

The series of studies conducted in the years 1999-2007 revealed that skin neoplasms other than melanoma malignum, pose a serious and increasing health threat in Poland, including the Silesia region [1,2]; the increase in incidence was dependent on the geographic location that is linked to UV exposure intensity $[3,4]$; the majority of skin neoplasms other than melanoma malignum were located in the exposed to sunshine parts of the body, including head and neck [5]. In the recent decade in Poland there is increase in awareness of negative effects of overexposure to UV radiation [6]. Electronic cigarettes were introduced, among other purposes also to limit the contact of chemical carcinogens and frequency of thermal injuries of lip skin - although both their efficacy in nicotine addiction cessation and general safety are still questioned [7]. Proper removal of skin lesions, always followed by microscopic examination of excised material, can be performed not only at dermatologic or surgical ambulatory, but sometimes even routinely at family doctor's office [8]. Unfortunately, early diagnostics of precancerous lesions is sometimes difficult [9] and treatment of advanced stage neoplasms of this region is demanding and the outcomes are often difficult to accept both functionally and aesthetically for patients [10].

The aim of the study was to find out trends in incidence of skin neoplasms other than melanoma in the Lower Silesia region of Poland to estimate the changes in relevant health risks as well as to indirectly evaluate the efficacy of prevention and education efforts undertaken by local public health authorities.

\section{MATERIAL AND METHODS}

Data on registered medical interventions because of skin neoplasms other than melanoma malignum (C44-C44.9 according to ICD-10) in the years 2006-2012, made available due to courtesy of the public healthcare insurance provider Narodowy Fundusz Zdrowia in Lower Silesia region of Poland (NFZ), were analysed in order to estimate yearly incidence of skin neoplasms other than melanoma malignum and current relevant trends in the Lower Silesia's population. The data were analysed with Microsoft Office Excel 2007 software. The structure of data did not allow broadening the analysis spectrum; especially data on age, sex or occupation of patients were not available. 
Robert Suslo et al. "Trends in Incidence of Skin Neoplasms other than Melanoma Malignum (C44 ICD10) in Lower Silesia Region of Poland in Years 2006-2012"

\section{RESULTS AND DISCUSSION}

The Lower Silesia region of Poland population did not change significantly in the years 2006-2012, even though some effects characteristic for population ageing were visible [11]. In the year 2014 in the region were living 2,9 million people, of which 52\% were females [12]. In the years 2006-2012 there were registered 59939 skin neoplasm cases of different kinds, other than malignant melanoma (C44-C44.9 according to ICD-10).

In the analysed period there were reported total 18161 cases of malignant neoplasms of skin other than: melanoma malignum, Kaposi sarcoma and neoplasms of genital organs, that were reported as general category only (C44 according to ICD-10). There was observed a consistent rising trend in incidence so in the year 2012 there amount of cases reached $313,0 \%$ of the initial value - as it is depicted in Figure 1.

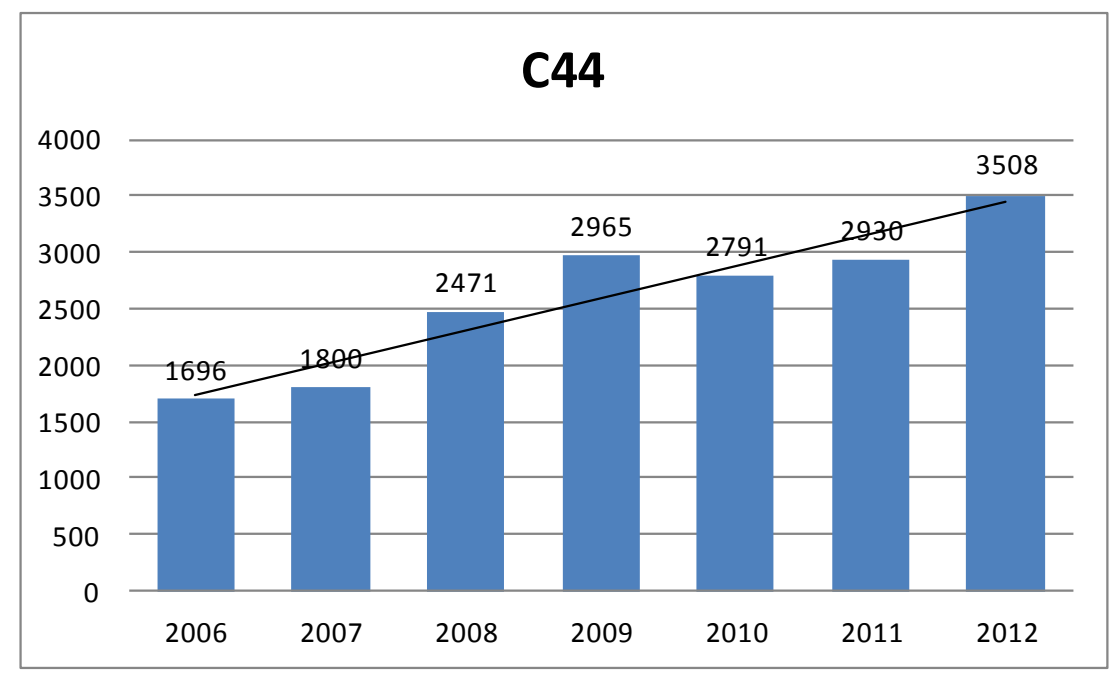

Figure1. Yearly Amounts of Cases of Malignant Neoplasms of Skin Other than: Melanoma Malignum, Kaposi Sarcoma and Neoplasms of Genital Organs, Reported as General Category Only (C44 According to ICD-10) Registered in the Lower Silesia Region of Poland in the Years 2006-2012; Source: Data Made Available by Courtesy of the NFZ.

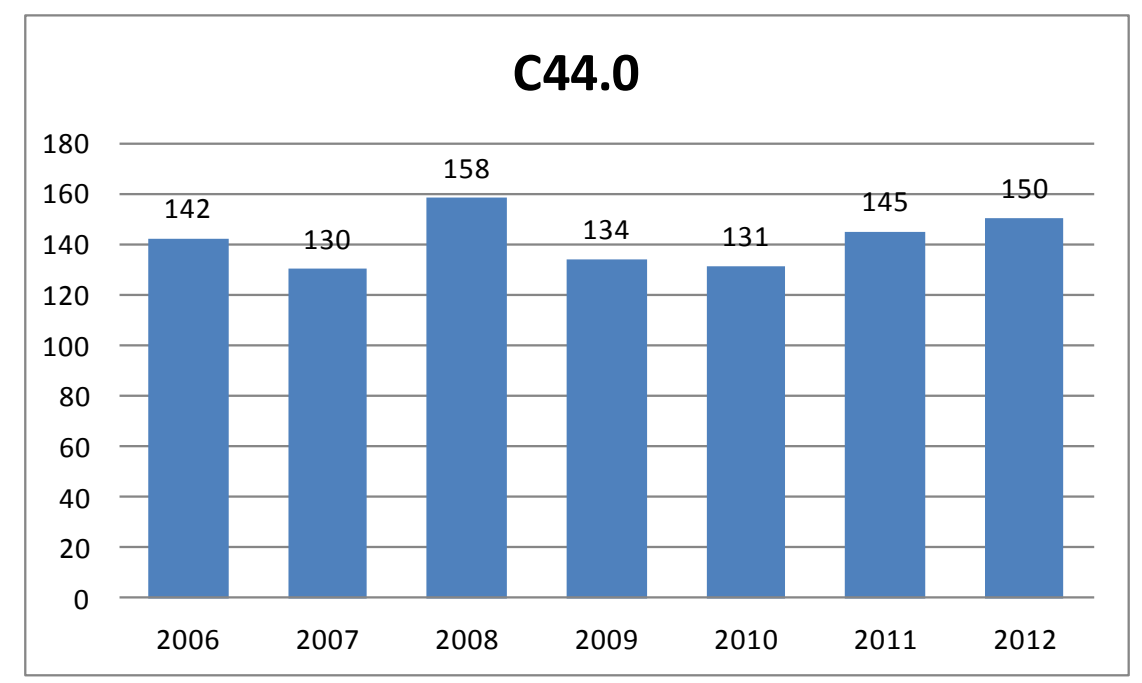

Figure2. Yearly Amounts of Cases of Basal Cell Carcinoma of Lip Skin (C44.0 According to ICD-10) Registered in the Lower Silesia Region of Poland in the Years 2006-2012; Source: Data Made Available by Courtesy of the NFZ.

The total amount of basal cell carcinoma of lip skin (C44.0 according to ICD-10) in the analysed period was 990 and it did not demonstrate any consistent trend - as it is presented in Figure 2. It shall be interpreted in the context cigarette smoking limitation efforts failure in Poland - despite of both public health and legal authorities efforts as well as of the migration of smokers to cigarettes equipped with filters and lately also electronic cigarettes - which are intended to limit the risk of both lip burns and contact with carcinogens. 
Robert Suslo et al. "Trends in Incidence of Skin Neoplasms other than Melanoma Malignum (C44 ICD10) in Lower Silesia Region of Poland in Years 2006-2012"

In the Lower Silesia region of Poland in the analysed years there were reported total 2381 cases of malignant neoplasms of skin of eyelid, including canthus and excluding connective tissue (C44.1 according to ICD-10). The yearly amounts of cases were alternating between the years, with marked rising trend: in the year 2012 the incidence was 143,3\% of the value from the year 2006, as it is demonstrated in the Figure 2.

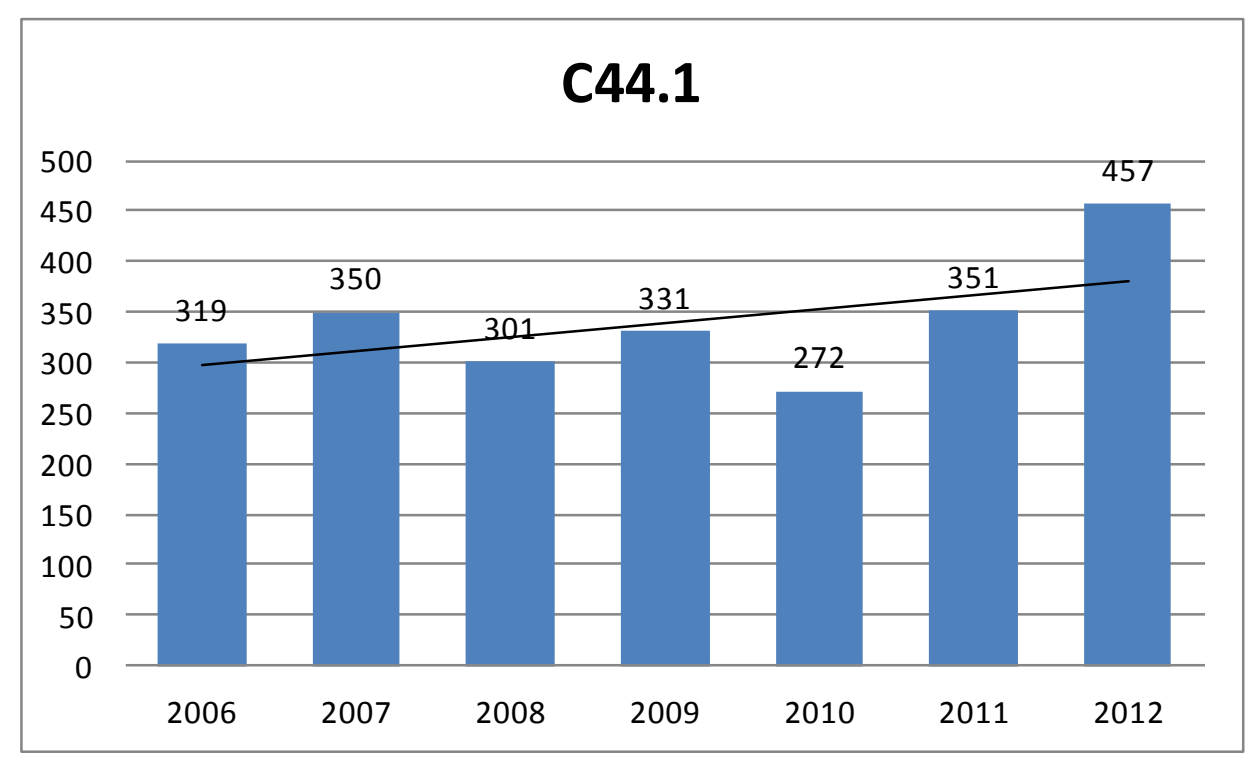

Figure3. Yearly Amounts of Cases of Malignant Neoplasms of Skin Of Eyelid, Including Canthus and Excluding Connective Tissue (C44.1 According to ICD-10) Registered in the Lower Silesia Region of Poland in the Years 2006-2012; Source: Data Made Available by Courtesy Of The NFZ.

Malignant neoplasms of skin of ear and external auricular canal, excluding connective tissue (C44.2 according to ICD-10) total count was 2109 in the analysed period. There was marked rising trend in yearly incidence, however with drop in the years 2010-2011 - as it is shown in Figure 4; in the year 2012 the cases amount was $151,4 \%$ of the initial value.

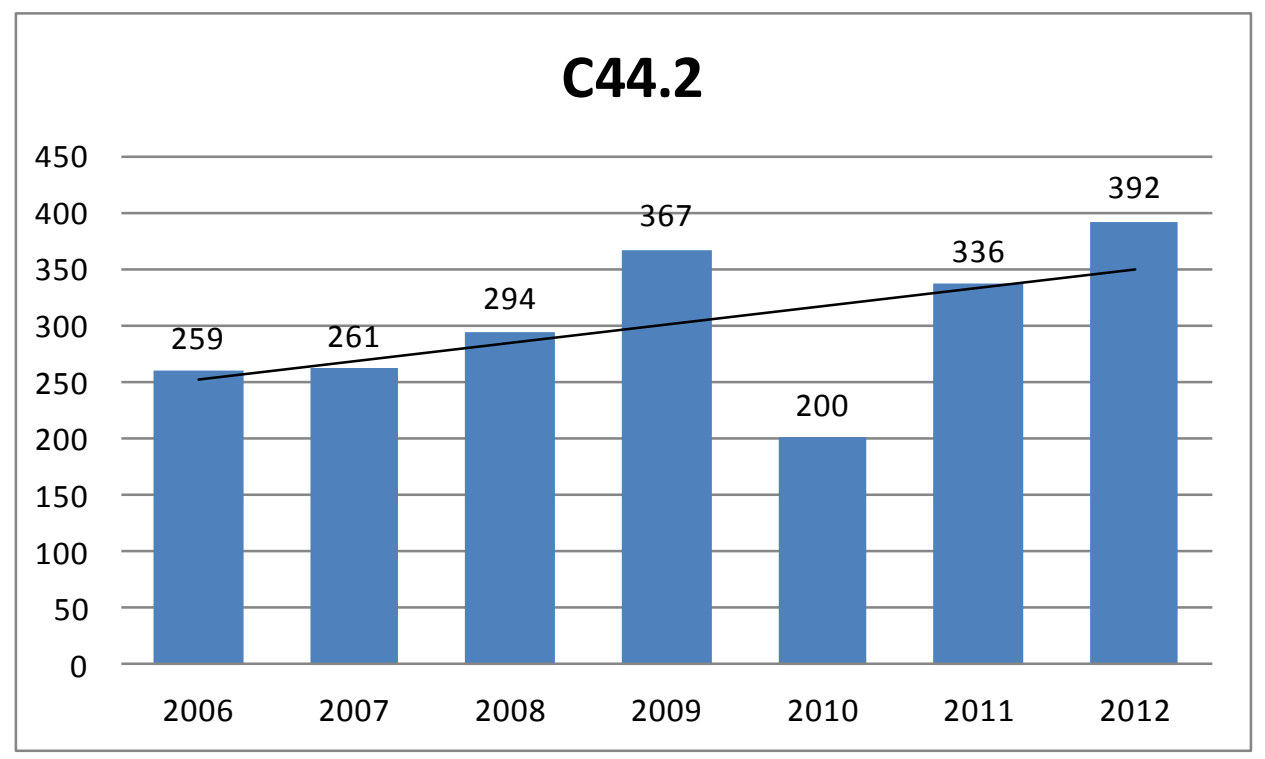

Figure4. Yearly Amounts of Cases of Malignant Neoplasms of Skin of Ear and External Auricular Canal, Excluding Connective Tissue (C44.2 According to ICD-10) Registered in the Lower Silesia Region of Poland in the Years 2006-2012; Source: Data Made Available by Courtesy of the NFZ.

There were 22414 cases of malignant neoplasms of skin of unspecified parts of face and its parts other than: lip, eyelid, ear and external auricular canal (C44.3 according to ICD-10) in the Lower Silesia region of Poland in the analysed period. The yearly incidence demonstrated rising trend with a small decline in the years 2010-2011 - as it is visible in the Figure 5; in the year 2012 the amount of cases was $189,9 \%$ of that from the year 2006. 
Robert Suslo et al. "Trends in Incidence of Skin Neoplasms other than Melanoma Malignum (C44 ICD10) in Lower Silesia Region of Poland in Years 2006-2012"

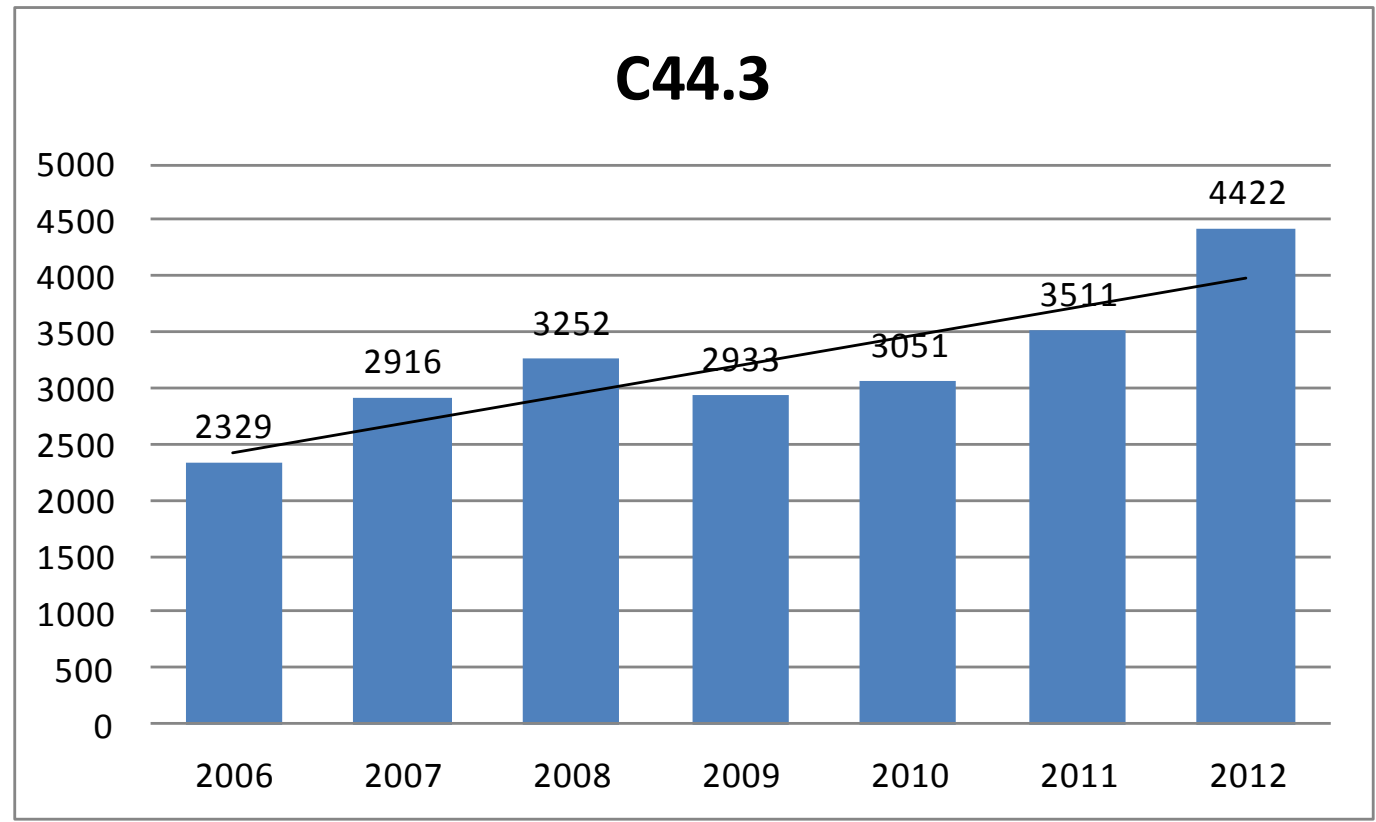

Figure5. Yearly Amounts of Cases of Malignant Neoplasms of Skin of Unspecified Parts of Face and Its Parts Other Than: Lip, Eyelid, Ear and External Auricular Canal (C44.3 According to ICD-10) Registered in the Lower Silesia Region of Poland in the Years 2006-2012; Source: Data Made Available by Courtesy of the NFZ.

Total amount of malignant neoplasms of skin of scalp and neck cases (C44.4 according to ICD-10) was 2545 in the analysed years. The yearly amount of such cases alternated through the most part of the analysed period to demonstrate significant increase in the end; in the year 2012 it was 145,8\% of the amount reported in the year 2006.

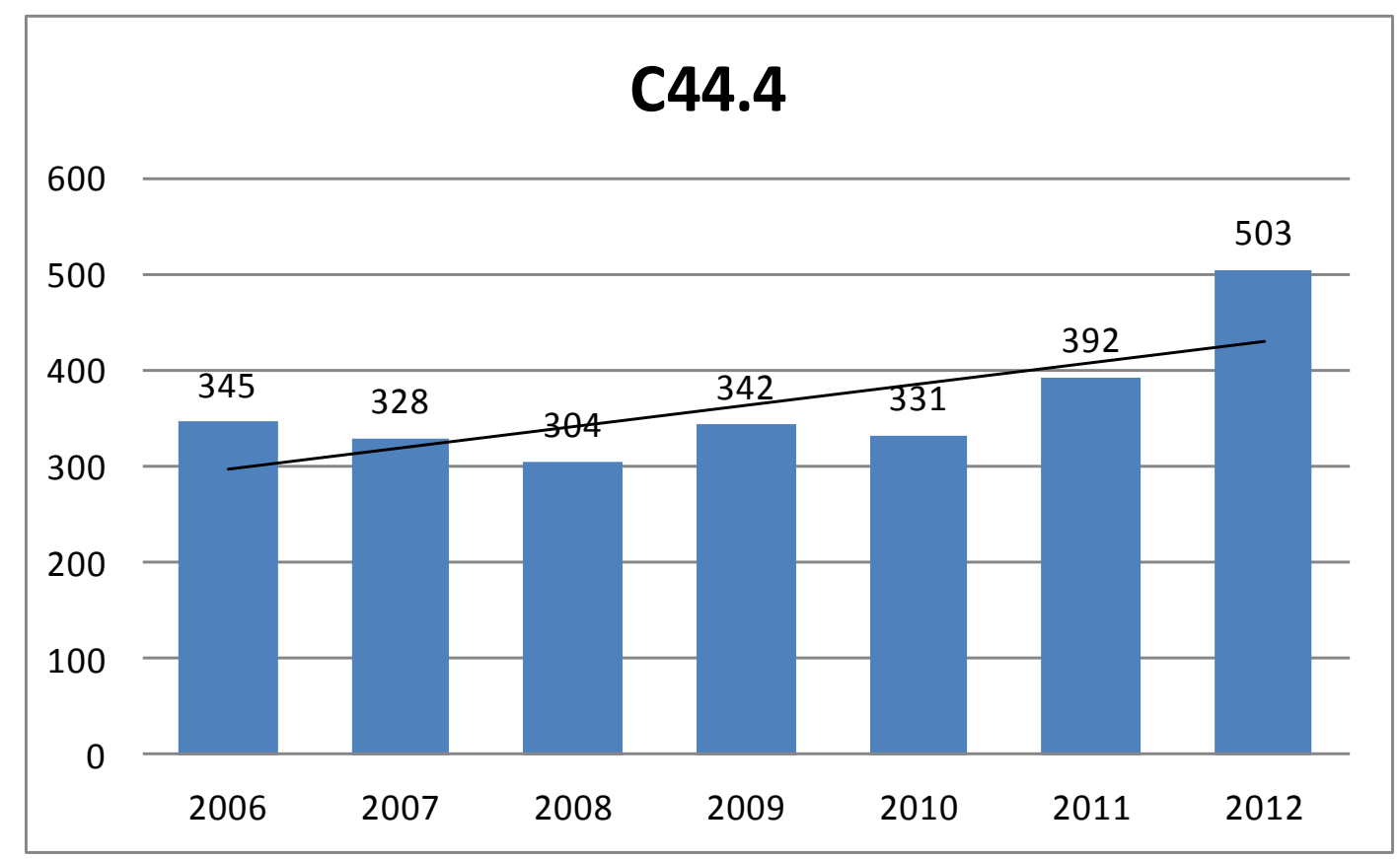

Figure6. Yearly Amounts of Cases of Malignant Neoplasms of Skin of Scalp and Neck (C44.4 According to ICD-10) Registered in the Lower Silesia Region of Poland in the Years 2006-2012; Source: Data Made Available by Courtesy of the NFZ.

In the years 2006-2012 there were reported total 4478 cases of malignant neoplasms of skin of trunk, including anal margin, perianal skin and skin of breast (C44.5 according to ICD-10) in the Lower Silesia region of Poland. The yearly amount of cases demonstrated consistent rising trend and in the year 2012 it increased to 186,4\% of the initial value - as it is visualised in Figure 7. 
Robert Suslo et al. "Trends in Incidence of Skin Neoplasms other than Melanoma Malignum (C44 ICD10) in Lower Silesia Region of Poland in Years 2006-2012"

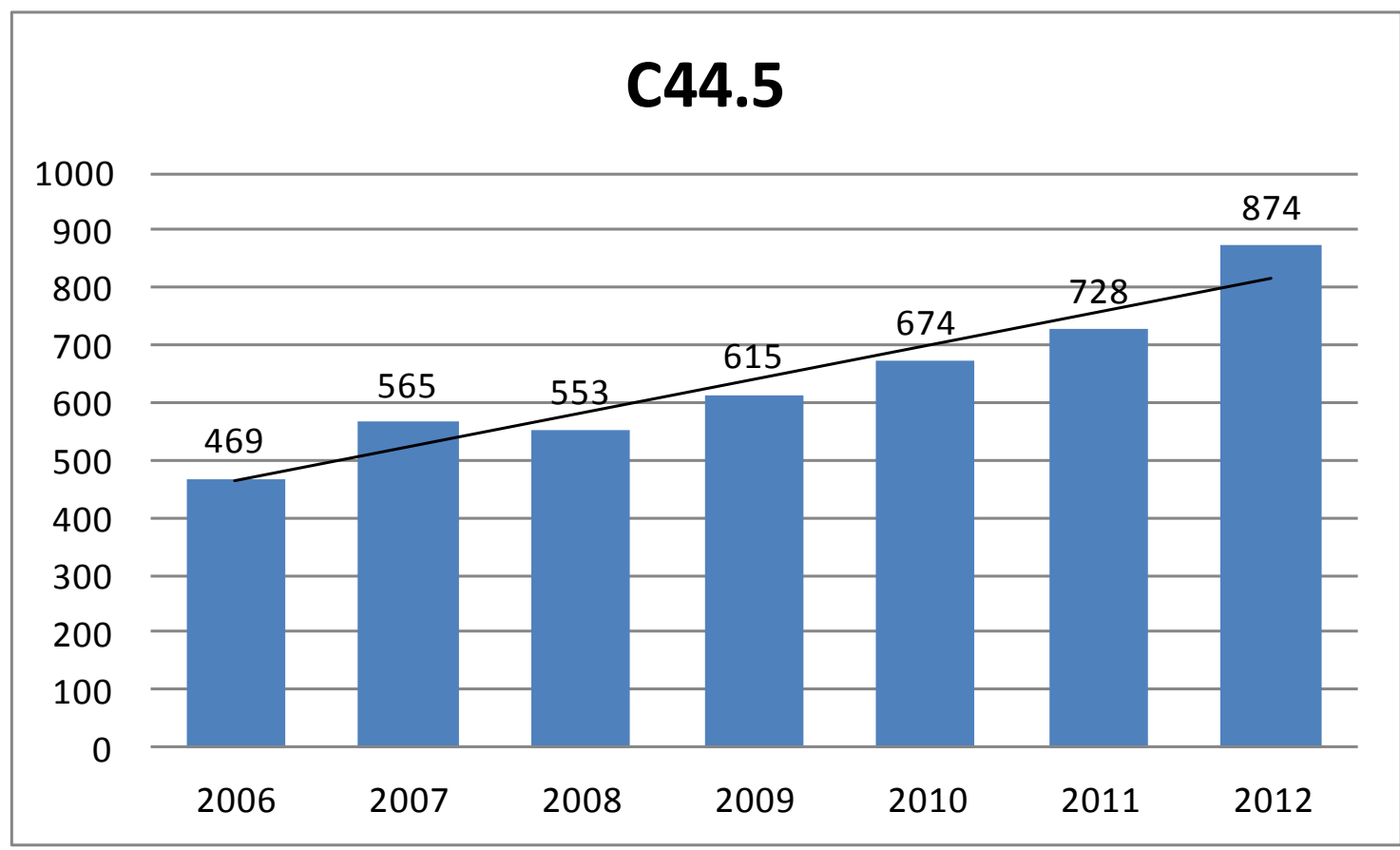

Figure7. Yearly Amounts of Cases of Malignant Neoplasms of Skin of Trunk, Including Anal Margin, Perianal Skin and Skin of Breast (C44.5 According to ICD-10) Registered in the Lower Silesia Region of Poland in the Years 2006-2012; Source: Data Made Available by Courtesy of the NFZ.

In the analysed years in the Lower Silesia region of Poland there were reported total 1586 cases of malignant neoplasms of skin of upper limb, including shoulder (C44.6 according to ICD-10). The yearly amount of cases alternated without any consistent trend - as it is demonstrated in Figure 8.

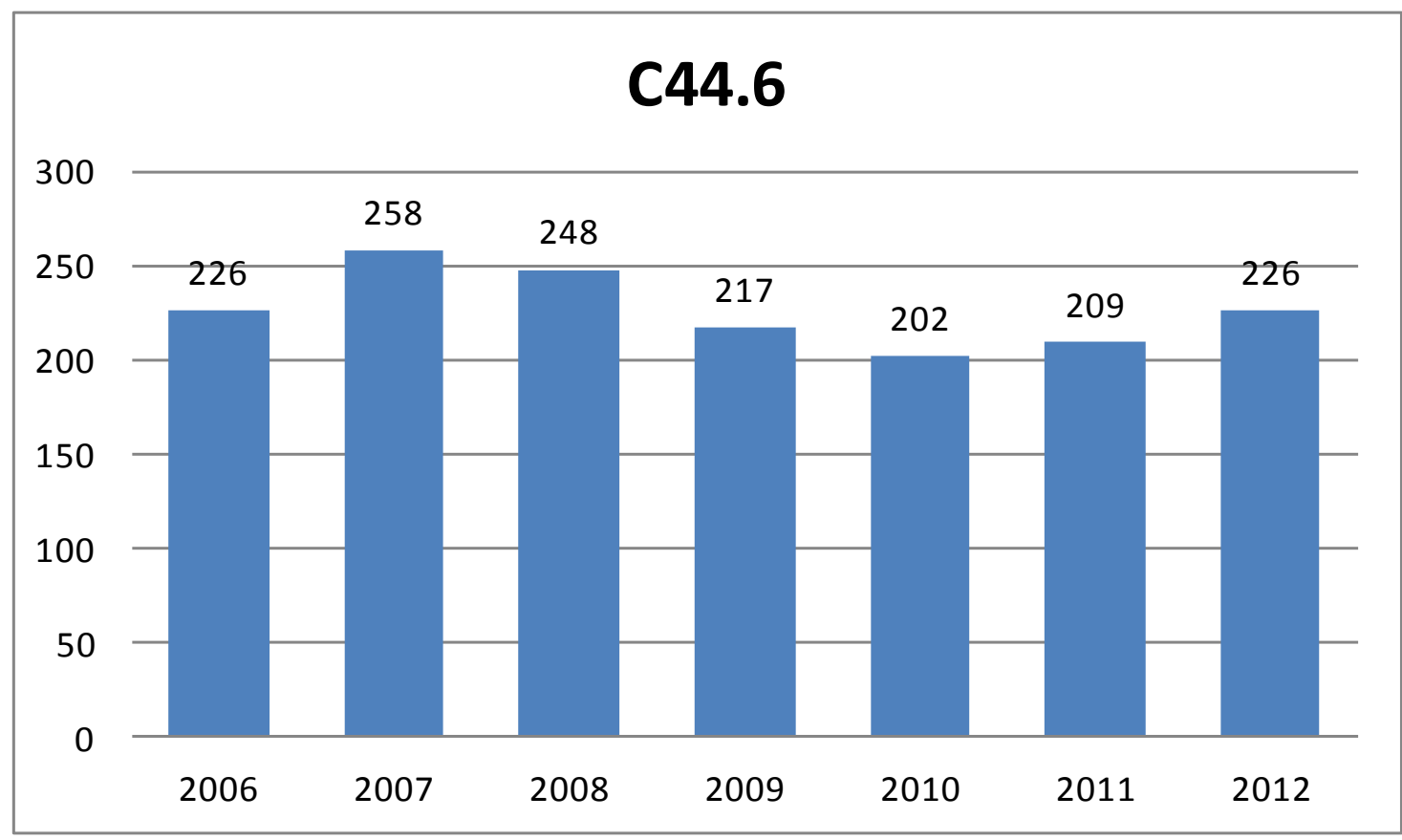

Figure8. Yearly Amounts of Cases of Malignant Neoplasms of Skin of Upper Limb, Including Shoulder (C44.6 According to ICD-10) Registered in the Lower Silesia Region of Poland in the Years 2006-2012; Source: Data Made Available by Courtesy of the NFZ.

Total count of malignant neoplasms of skin of lower limb, including hip (C44.7 according to ICD-10) cases was 2007 in the analysed years. The yearly cases amount increased in the end of the period and in the year 2012 it was $132,8 \%$ of the year 2006 value - as it is visualised in Figure 8. 
Robert Suslo et al. "Trends in Incidence of Skin Neoplasms other than Melanoma Malignum (C44 ICD10) in Lower Silesia Region of Poland in Years 2006-2012"

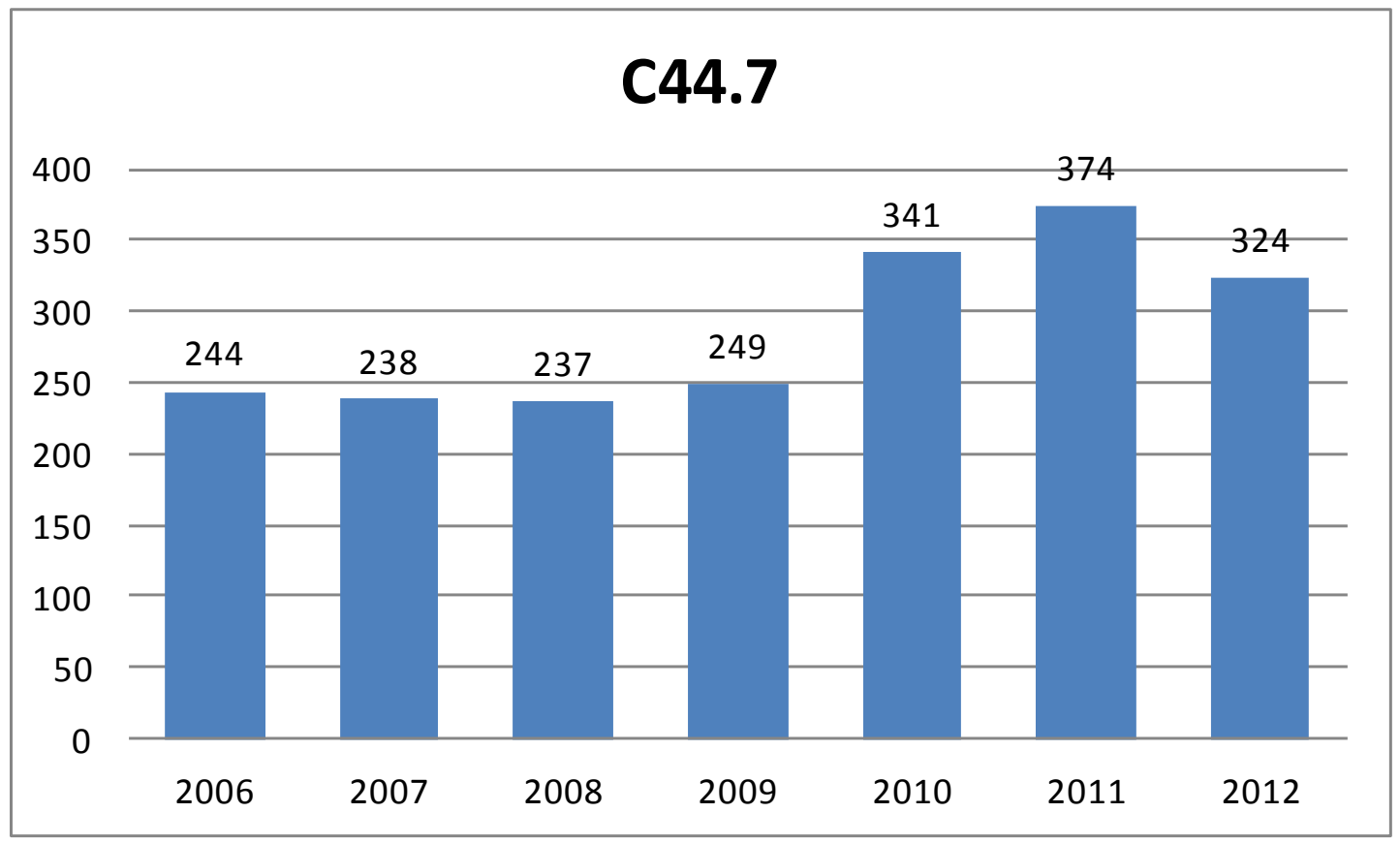

Figure8. Yearly Amounts of Cases of Malignant Neoplasms of Skin of Lower Limb, Including Hip (C44.7 According to ICD-10) Registered in the Lower Silesia Region of Poland in the Years 2006-2012; Source: Data Made Available by Courtesy of the NFZ.

Malignant neoplasms - overlapping lesions of skin (C44.8 according to ICD-10) were rarely reported the total amount of cases in the years 2006-2012 was 272; in the initial part of the analysed period the yearly cases amount demonstrated a dropping trend, with a significant rise in the year 2012 - as it is shown in Figure 9.

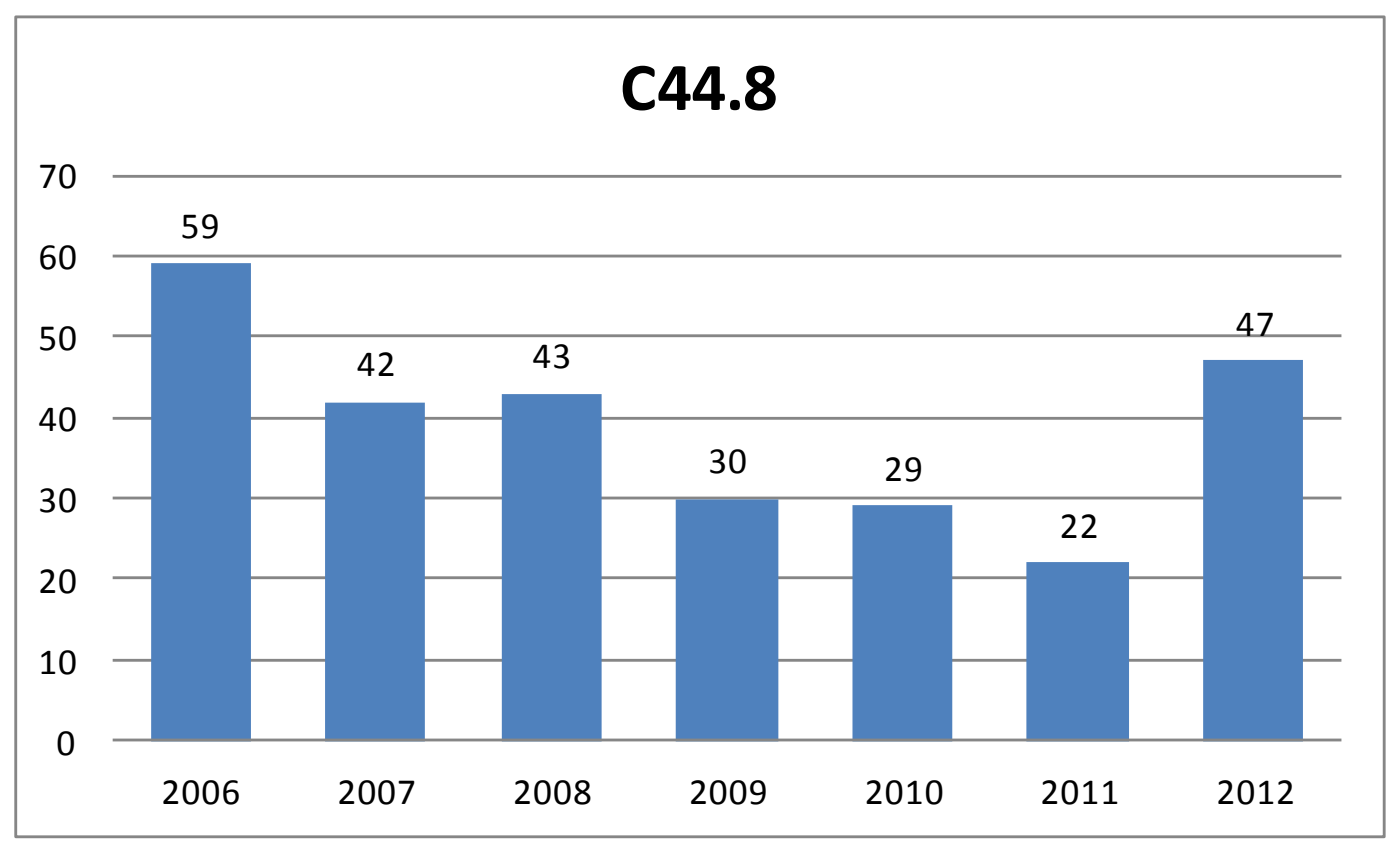

Figure9. Yearly Amounts of Cases of Malignant Neoplasms - Overlapping Lesions of Skin (C44.8 According to ICD-10) Registered in the Lower Silesia Region of Poland in the Years 2006-2012; Source: Data Made Available by Courtesy of the NFZ.

The total amount of cases of unspecified malignant neoplasms of skin (C44.9 according to ICD-10) was 2996 in the analysed years. The yearly amount of cases rose in the beginning of the period and after the year 2009 alternated; in the year 2012 it was $200,4 \%$ of the year 2006 value - as it is visualised in Figure 10. 


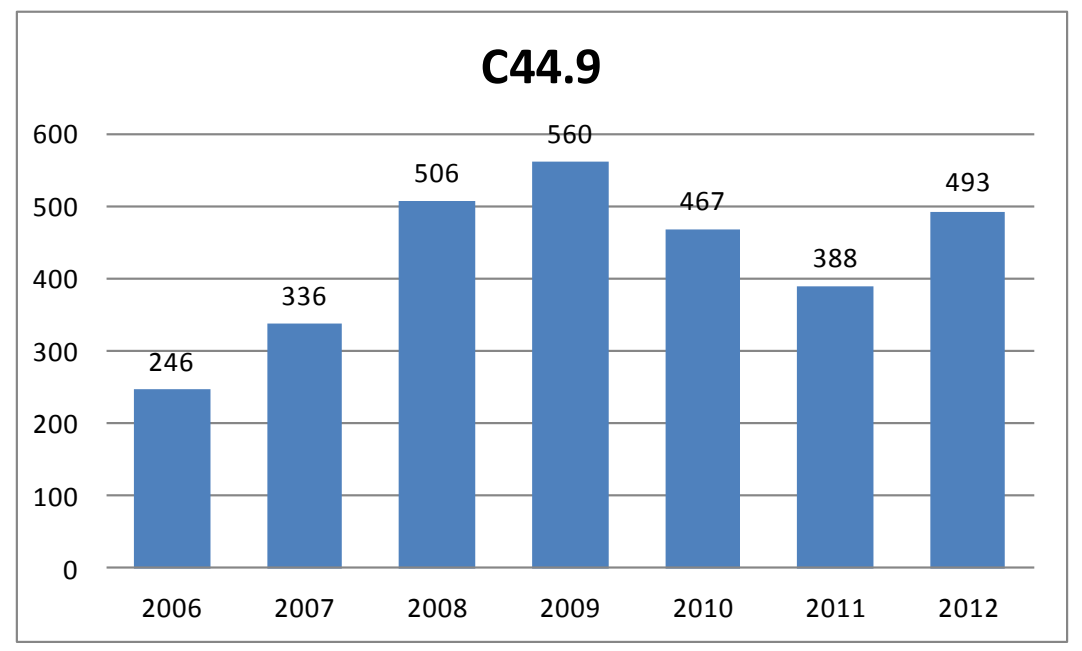

Figure10. Yearly Amounts of Cases of Unspecified Malignant Neoplasms of Skin (C44.9 According to ICD-10) Registered in the Lower Silesia Region of Poland in the Years 2006-2012; Source: Data Made Available by Courtesy of the NFZ.

Comparison of the data on the beginning and the end of the analysed period, as it is put together in Figure 10, demonstrates dynamic increase in the total yearly amount of cases belonging to the general category of malignant neoplasms of skin other than: melanoma malignum, Kaposi sarcoma and neoplasms of genital organs (C44-C44.9 according to ICD-10) - from 6334 in the year 2006 to 11396 in the year 2012, which is $179,9 \%$ of the initial vaule. The rise is visible in all subcategories but two least numerous, and the biggest case amount increase is demonstrated by the most rife categories: other than melanoma malignum neoplasms of skin of unspecified parts of face and its parts other than lip, eylid, ear and external auricular canal; other than melanoma malignum neoplasms of skin reported as general category, and neoplasms of trunk skin (C44.3, C44, C44.5 according to ICD-10, respectively).

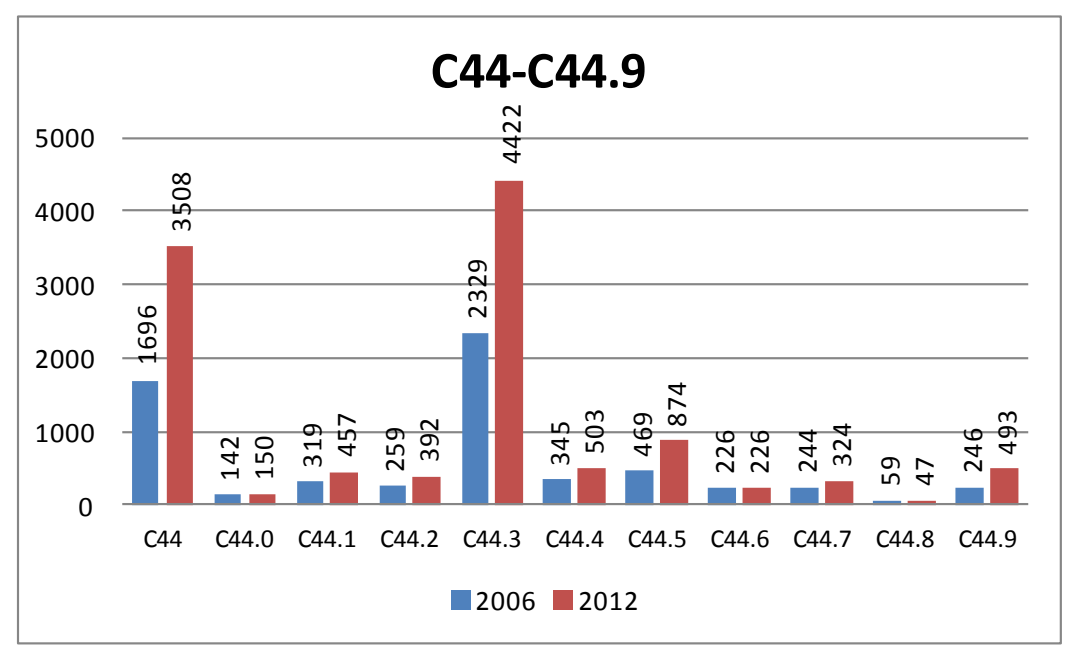

Figure10. Yearly Amounts of Cases of Malignant Neoplasms of Skin Other than: Melanoma Malignum, Kaposi Sarcoma and Neoplasms of Genital Organs Genaral Category (C44-C44.9 According to ICD-10) Registered in the Lower Silesia Region of Poland in the Years 2006 and 2012; Source: Data Made Available by Courtesy of the NFZ.

\section{CONCLUSIONS}

The study revealed that in the Lower Silesia region of Poland there was in the years 2006-2012 dynamic increase in the total yearly amount of cases belonging to the general category of malignant neoplasms of skin other than: melanoma malignum, Kaposi sarcoma and neoplasms of genital organs (C44-C44.9 according to ICD-10) and the most commonly reported location of these skin neoplasms was the face, far less often it was also: trunk, scalp and neck. It is a very important signal for dermatologists in the first place, but also for all other medical personnel, as well as for Polish public health authorities, that screening efforts should be intensified to detect suspicious skin lesions 
early so chances for successful treatment are maximised. As it is known that intense exposure to ultraviolet radiation, especially early in life, increase the risk of skin malignancies other than melanoma malignum - the education efforts need to be further increased in Poland to convince the general population to limit exposure to intense sunshine and frequency of solarium use, especially in children.

\section{REFERENCES}

[1] Juszko-Piekut M, Mozdzierz A, Kolosza Z, Kroolikowska-Jeruzalska M, Wawro-Bielecka P, Kowalska-Ziomek G, Olczyk D, Stojko J, Incidence of Melanoma and Non-Melanoma Skin Cancer in the Inhabitants of the Upper Silesia, Poland in: Highlights in Skin Cancer, ed. Vereecken P, InTech, 2013, DOI: http://dx.doi.org/10.5772/55239

[2] Juszko-Piekut M Mozdzierz A, Kolosza Z, Olczyk D, Stojko J, Nonmelanoma skin cancer incidence in the inhabitants of Bielsko-Biała subregion in Silesia Voivodeship in the years 19992005, Environmental Medicine, 2014, 17, 4, PP: 54-62 Available: http://www. Medycyna srod owiskowa.p1/Downloads/File/2014v4/MS_2014-4_6.pdf

[3] Juszko-Piekut M, Kolosza Z, Mozdzierz A, Stojko J, Olczyk D, Incidence of melanoma malignum and non-melanoma cancer of the skin in male inhabitants of Silesian Voivodeship (including two subregions of diverse UV exposure) in 1999-2003, Polish J Environ Stud 2006; 15, 2B, PP: 1175-1181

[4] Juszko-Piekut M, Kolosza Z, Mozdzierz A, Zemla B: Incidence of non-melanoma skin cancer in the population of the Silesian Voivodeship (including industrial subregions central and Rybnicko-Jastrzębski) in the years 1999-2005, Environmental Medicine, 2007; 10, 2, PP:46-53

[5] Juszko-Piekut M, Kolosza Z, Mozdzierz A, Zemla B, Stojko J, The incidence of malignant nonmelanoma skin cancer in the inhabitants of the silesian voivodeship, Family Medicine \& Primary Care Review 2008, 10, 4, PP: 1286-1290 Available: http://www. familymedreview. org/files/2008/pdf_042008/2_original_papers_1267_1315.pdf

[6] Grywalska E, Kowal A, Chmiel-Perzynska I, Derkacz M, Is the knowledge of harmfulness of the overexposure of the skin to UV radiation sufficient? Family Medicine \& Primary Care Review, 2009, 11, 3; PP: 326-329 Available: http://www.familymedreview.org/files/2009/pdf_ 032009/2_original_papers_245_397.pdf

[7] Shrestha G, Electronic cigarette: are we introducing its use too early? ARC Journal of Public Health and Community Medicine, 2016, 1, 2, PP:7-8 DOI: http://dx.doi.org/10.20431/24560596.0102002

[8] Suslo R, Drobnik J, Basic issues of ambulatory surgery IN: Practical skills for primary care physicians; ed. Andrzej Steciwko, Akademia Medyczna im. Piastow Slaskich, Wrocław, 2011; PP: $171-178$

[9] Drobnik J, Jadach R, Sender-Janeczek A, Siwek-Jadach K, Suslo R, Trudnosci diagnostyczne stanow przednowotworowych na przykladzie przypadku zapalenia warg Manganottiego, Med Ogolna, 2007, 13, 4, PP: 321-327

[10] Drobnik J, Luczak K, Jadach R, Suslo R, Steciwko A, Trnka J, Quality of life after treatment of advanced mouth region neoplasms as a multidisciplinary problem, Bad Nauk, 2007, 21, 2; PP: 13-16.

[11] Drobnik J, Suslo R, Kurpas D, Trnka J.: Analysis of elderly people care system and their health needs in the Lower Silesia region; Fam.Med.Prim.Care Rev., 2010, 12, 2; PP: 165-167 http://www.familymedreview.org/files/2010/pdf_022010/2_original_papers_127_312.pdf

[12] Central Statistical Office of Poland Information Portal http://stat.gov.pl/statystyka-regionalna/ rankingi-statystyczne/ludnosc-wedlug-wojewodztw/ [accessed: 10.08.2016]

Citation: Suslo R, Drobnik J, Michalska M. Trends in Incidence of Skin Neoplasms other than Melanoma Malignum (C44 ICD-10) in Lower Silesia Region of Poland in Years 20062012. International Journal of Research Studies in Medical and Health Sciences. 2016;1(1):15-22

Copyright: (C) 2016 Suslo R, et al. This is an open-access article distributed under the terms of the Creative Commons Attribution License, which permits unrestricted use, distribution, and reproduction in any medium, provided the original author and source are credited. 